\title{
Effect of Rate Control on Speech Production and Intelligibility in Dysarthria
}

\author{
Gwen Van Nuffelen Marc De Bodt Jan Vanderwegen Paul Van de Heyning \\ Floris Wuyts \\ Antwerp University Hospital, Edegem, Belgium
}

\section{Key Words}

Rate control methods - Speaking rate $\cdot$ Articulation rate Intelligibility · Pause characteristics

\begin{abstract}
The reported study investigated the effect of 7 rate control methods (RCM) on running speech intelligibility, speaking rate (SR), articulation rate (AR) and pause characteristics in 27 individuals with dysarthria. The data reveal that with the exception of slower on demand, each RCM resulted in lower mean SRs and ARs $(p<0.05)$. Clinically significant improvements in intelligibility were found in half of the participants with different types of dysarthria. The majority of them had normal or decreased ARs and SRs. The most effective methods were: alphabet board, hand tapping and pacing board. For the majority of speakers, the maximal decrease in speech rate was not associated with the maximal increase in intelligibility.

Copyright $\odot 2010$ S. Karger AG, Basel
\end{abstract}

\section{Introduction}

Speech rate is often considered as a powerful modifiable variable for improving the intelligibility of dysarthric speech [1-3]. The correlation between rate and intelligibility, however, is not straightforward and depends on several (unknown) variables. Whereas several studies have demonstrated a positive effect of a specific rate control method (RCM) on intelligibility in dysarthria, others did not find such an effect, and 2 studies even found the opposite effect. When clustering all the data provided in these papers, there is an indication that pacing is a more effective method than delayed auditory feedback and speaking slower on demand. However, since all studies used different patients and methods, this has no scientific value. In their 2007 systematic review of evidence on the effectiveness of treatment of loudness, rate and prosody in dysarthria, Yorkston et al. [4] indicated that treatment studies comparing various RCMs would be necessary in the future. In 2008, Van Nuffelen et al. [5] published a study that compared the effect of 7 RCMs on articulation rate (AR), speaking rate (SR) and intelligibility in dysarthria. The 7 methods were: speaking slower on demand, pacing board, alphabet board, hand tapping, delayed auditory feedback with delays of $50 \mathrm{~ms}$ (DAF50), $100 \mathrm{~ms}$ (DAF100) and $150 \mathrm{~ms}$ (DAF150). The

\section{KARGER \\ Fax +41613061234 E-Mail karger@karger.ch} www.karger.com
Van Nuffelen Gwen

ORL Department, Antwerp University Hospital

Bankwegelhof 81

BE-9120 Beveren (Belgium)

Tel. +32 382134 85, Fax +32 382144 51, E-Mail gwen.van.nuffelen@uza.be 
authors found that, with exception of speaking slower on demand, all methods significantly reduced AR and SR. Strikingly, all reduced the mean intelligibility of the whole dysarthric population. In cases of DAF100 and DAF150, the decrease was even significant. However, analysis of the individual data showed a clinically significant increase in intelligibility in 5 out of 19 participants. The methods that led to a clinically significant increase were hand tapping, speaking slower on demand, alphabet board and pacing board. At the 28th International IALP Congress, held in August 2010 in Athens, the authors discussed their data (which had been extended) more thoroughly, including information on method-specific pause characteristics and determination of ideal speech rate. These data are presented in this paper.

The following research questions were addressed:

(1) What is the effect of various RCMs on AR and SR?

(2) What is the effect of various RCMs on total pause duration, mean pause duration and pause frequency?

(3) What is the effect of various RCMs on intelligibility?

(4) Does the effect of rate control on intelligibility depend on habitual speech rate, type of dysarthria and/or severity of dysarthria?

(5)Does the maximal decrease in speech rate result in a maximal increase in intelligibility and can we define an ideal speech rate?

\section{Methods}

The methods used in the current study are in accordance with the methods used in the previous study [5].

\section{Participants}

The presented data are based on 27 participants ( 22 men, 5 women, mean age: 64 years, range: $17-88$ years). Individuals with a habitual intelligibility level above $90 \%$ were excluded. All participants reported adequate language, hearing and visual abilities. The etiology of dysarthria varied among the participants. Detailed information for each patient concerning age, gender, type, etiology of dysarthria, severity of dysarthria, habitual SR and habitual AR is presented in table 1 .

\section{Rate Control Methods}

The mutually compared RCMs were speaking slower on demand, alphabet board, hand tapping, pacing board, DAF50, DAF100 and DAF150. Prior to each method, the participants were given clear instructions. In case of speaking slower on demand, the participants were asked to speak half as fast as they were used to. In case of the alphabet board, the participants were instructed to indicate the first grapheme of each word on the board before uttering the word. Using the pacing board, the participants had to touch one square for each pronounced word (uttering word per word) and in case of hand tapping they were asked to tap once for each syllable (uttering syllable per syllable).

\section{Text Passages}

For this task, 20 different passages with simple sentence constructions and without any difficult word choices or reading level [6] were used. Seven (mean sentence length: 9 words; mean word length: 1.34-1.39 syllables) or 8 (mean sentence length: 10 words; mean word length: 1.38-1.44 syllables) were selected. For each method, the participants were asked to read a randomly selected reading passage for at least $2 \mathrm{~min}$.

\section{Speech Samples}

Two-minute samples were recorded in each of the 8 assessed conditions. Each subject started with habitual SR, followed by the 7 RCMs. The sequence of the RCMs was randomized and differed between participants. The speech samples were recorded in a quiet environment by means of a notebook and a freely available wave editor (Audacity ${ }^{\circledR}$ ). The mouth to microphone (Sony ECM-717) distance measured $300 \mathrm{~mm}$. The digital speech samples had a sampling frequency of $44 \mathrm{kHz}$. Each sample was saved as a separate wave file.

\section{Intelligibility Ratings}

The intelligibility of the speech samples was rated by 3 speech language pathologists with experience in dysarthria. They were not familiar with the reading passages. Accordingly to a previously used definition of intelligibility [7-10], the listeners were instructed to indicate the degree to which they understood the utterances produced by the speaker on a $100-\mathrm{mm}$ visual analogue scale. The listeners were asked to exclude perceptual judgments of naturalness, voice quality, pitch and so forth from the intelligibility rating. The extremities of the scale were respectively labeled as completely unintelligible and completely intelligible. Listeners reported normal hearing, and were native speakers of Dutch.

The 216 samples $(27$ participants $\times 8$ conditions) were randomly played back by means of Windows Media Player, installed on a notebook (HP pavilion ze4600). As the samples were judged by all the listeners simultaneously, speakers (Logitech) were used to present the samples at a sound pressure level of 75-80 $\mathrm{dB}$.

\section{Inter-Rater Reliability for the Intelligibility Ratings}

The inter-rater reliability for the intelligibility ratings was determined for all 216 samples by means of an intraclass correlation coefficient. Strong inter-rater reliability was found (0.85). The mean error rate was $8 \%$, meaning that an increase in intelligibility of $>8 \%$ can be interpreted as clinically significant.

\section{Total Pause Duration, Mean Pause Duration and Pause}

\section{Frequency}

The samples were analyzed by means of the freely available wave-editor Audacity. Calculations of total pause duration, mean pause duration and pause frequency were based on silent pauses (a silent pause is defined as a silent fragment of at least $200 \mathrm{~ms}$ ). Filled pauses were not included.

The total pause duration, expressed in milliseconds, is the sum of the duration of all silent pauses occurring in the 1-min sample. 
Table 1. Participants' characteristics, habitual SR and AR

\begin{tabular}{|c|c|c|c|c|c|c|c|}
\hline $\begin{array}{l}\text { Participant } \\
\text { No. }\end{array}$ & Gender & $\begin{array}{l}\text { Age } \\
\text { years }\end{array}$ & Etiology & Subtype & $\begin{array}{l}\text { Severity of } \\
\text { dysarthria }\end{array}$ & $\begin{array}{l}\text { Habitual SR } \\
\text { syllables/s }\end{array}$ & $\begin{array}{l}\text { Habitual AR } \\
\text { syllables/s }\end{array}$ \\
\hline 1 & M & 24 & $\mathrm{MD}$ & flaccid & mild & 2.48 & 3.73 \\
\hline 2 & $\mathrm{~F}$ & 17 & trauma & UUMN & mild & 3.52 & 5.54 \\
\hline 3 & $\mathrm{~F}$ & 34 & trauma & flaccid & moderate & $0.93^{2}$ & $2.51^{2}$ \\
\hline 4 & M & 54 & stroke & ataxic & mild & 3.27 & 4.24 \\
\hline 5 & M & 58 & stroke & hypokinetic & mild & 2.73 & 5.86 \\
\hline 6 & M & 61 & $\mathrm{PD}$ & hypokinetic & mild & 3.00 & $8.96^{1}$ \\
\hline 7 & $\mathrm{~F}$ & 52 & stroke & ataxic & moderate & $1.42^{2}$ & $2.02^{2}$ \\
\hline 8 & M & 57 & stroke & UUMN & mild & 3.10 & 4.53 \\
\hline 9 & $\mathrm{M}$ & 72 & stroke & UUMN & mild & 3.47 & 4.99 \\
\hline 10 & M & 72 & stroke & UUMN & mild & 2.62 & 3.68 \\
\hline 11 & $\mathrm{~F}$ & 78 & stroke & UUMN & moderate & 2.30 & 3.50 \\
\hline 12 & $\mathrm{M}$ & 88 & $\mathrm{PD}$ & hypokinetic & mild & 2.88 & 4.37 \\
\hline 13 & $\mathrm{M}$ & 78 & $\mathrm{PD}$ & hypokinetic & mild & 3.43 & $6.14^{1}$ \\
\hline 14 & M & 86 & $\mathrm{PD}$ & hypokinetic & severe & 2.43 & 5.32 \\
\hline 15 & $\mathrm{M}$ & 82 & stroke & UUMN & mild & $2.10^{2}$ & $2.92^{2}$ \\
\hline 16 & M & 78 & $\mathrm{PD}$ & hypokinetic & severe & $4.97^{1}$ & 5.08 \\
\hline 17 & $\mathrm{M}$ & 62 & stroke & spastic & moderate & 2.30 & $3.39^{2}$ \\
\hline 18 & $\mathrm{M}$ & 63 & $\mathrm{PD}$ & hypokinetic & moderate & $4.73^{1}$ & 5.39 \\
\hline 19 & $\mathrm{M}$ & 61 & stroke & UUMN & moderate & 4.20 & 4.83 \\
\hline 20 & $\mathrm{~F}$ & 83 & stroke & UUMN & moderate & 4.26 & 4.80 \\
\hline 21 & $\mathrm{M}$ & 60 & stroke & UUMN & moderate & 3.63 & 3.98 \\
\hline 22 & $\mathrm{M}$ & 59 & ALS & mixed & moderate & $1.93^{2}$ & $3.18^{2}$ \\
\hline 23 & $\mathrm{M}$ & 77 & stroke & mixed & severe & 4.01 & 4.30 \\
\hline 24 & M & 82 & stroke & hypokinetic & moderate & 3.34 & 3.57 \\
\hline 25 & $\mathrm{M}$ & 69 & stroke & UUMN & mild & $2.28^{2}$ & 3.93 \\
\hline 26 & $\mathrm{M}$ & 69 & PSP & hypokinetic & moderate & $1.66^{2}$ & $2.19^{2}$ \\
\hline 27 & $\mathrm{M}$ & 55 & stroke & ataxic & moderate & 4.17 & 4.22 \\
\hline
\end{tabular}

$\mathrm{MD}=$ Myotonic dystrophy; UUMN = unilateral upper motor neuron; PD = Parkinson's disease; ALS = amyotrophic lateral sclerosis; PSP = progressive supranuclear palsy.

${ }^{1}$ Exceeds the upper boundary of the $95 \%$ prediction interval of the control group.

${ }^{2}$ Lower than the lower boundary of the $95 \%$ prediction interval of the control group.

Pause frequency is defined as the number of pauses per minute.

The mean pause duration, also expressed in milliseconds, was obtained by dividing the total pause duration by the pause frequency.

\section{Results}

\section{Effect of Rate Control on SR}

Figure 1 shows the mean SRs of the dysarthric group for the 7 examined speech RCMs. A significant effect of methods was found ( $\mathrm{p}<0.001)$. Pairwise comparison showed that each RCM, with the exception of speaking slower on demand, resulted in significantly lower mean
SRs when compared with the habitual rate $(\mathrm{p}<0.001$; $\mathrm{p}<0.05$ for DAF100). It should be noted that although the participants were instructed to speak half as fast as they were used to, mean SR was only reduced by $9.3 \%$.

The slowest mean SRs were obtained by hand tapping, alphabet board and pacing board.

\section{Effect of Rate Control on AR}

Figure 1 also presents the mean ARs of the dysarthric population for habitual reading and the 7 RCMs. The effect of methods was highly significant ( $p<0.001)$. Pairwise comparison pointed out that each RCM significantly reduced AR ( $p<0.001)$ with the exception of speaking slower on demand. 
Fig. 1. Habitual and modified ARs and SRs of the dysarthric population. Data presented as means $\pm \mathrm{SE}$.

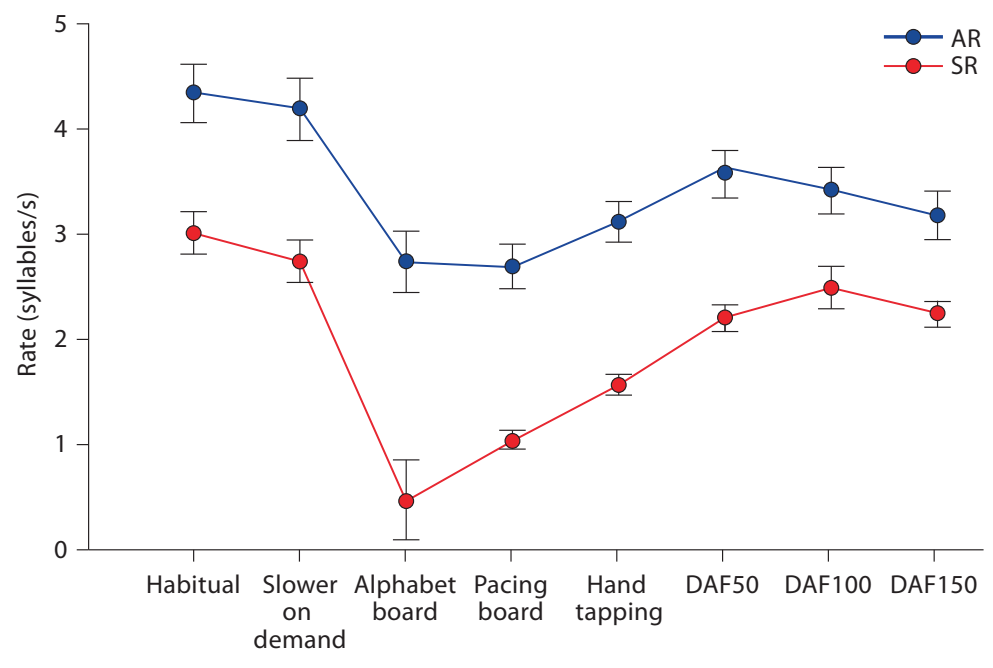

Table 2. Effect of the investigated RCMs on total pause duration, mean pause duration and pause frequency

\begin{tabular}{llll}
\hline & $\begin{array}{l}\text { Total pause } \\
\text { duration, ms }\end{array}$ & $\begin{array}{l}\text { Mean pause } \\
\text { duration, ms }\end{array}$ & $\begin{array}{l}\text { Pause } \\
\text { frequency }\end{array}$ \\
\hline Habitual & $21,907.12$ & $1,012.02$ & 22.63 \\
Demand & $24,511.13$ & $1,042.06$ & 24.74 \\
Alphabet board & $46,829.96$ & $3,016.97$ & 17.04 \\
Pacing board & $34,573.07$ & $1,345.87$ & 29.54 \\
Hand tapping & $25,476.22$ & 873.33 & 33.00 \\
DAF50 & $20,771.15$ & 916.66 & 23.04 \\
DAF100 & $22,540.75$ & 994.14 & 23.74 \\
DAF150 & $21,473.70$ & 842.04 & 25.93 \\
\hline
\end{tabular}

Speaking slower on demand only reduced AR by $3.7 \%$ on average.

AR was most effectively reduced by the following methods: hand tapping, alphabet board and pacing board.

\section{Effect on Total Pause Duration, Mean Pause \\ Duration and Pause Frequency}

Tables 2 and 3 summarize the effect of the 7 RCMs on total pause duration, mean pause duration and pause frequency. Total pause duration was only significantly increased when using an alphabet board or pacing board $(p<0.001)$ and only the use of the former resulted in a
Table 3. Visualization of the effect of the investigated RCMs on articulation rate, total pause duration, mean pause duration and number of pauses

\begin{tabular}{lllll}
\hline & $\begin{array}{l}\text { Articula- } \\
\text { tion rate }\end{array}$ & $\begin{array}{l}\text { Total pause } \\
\text { duration }\end{array}$ & $\begin{array}{l}\text { Mean pause } \\
\text { duration }\end{array}$ & $\begin{array}{l}\text { Pause } \\
\text { frequency }\end{array}$ \\
\hline Demand & & & & \\
Alphabet board & $\downarrow^{* *}$ & $\uparrow^{* *}$ & $\uparrow^{* *}$ & $\downarrow^{*}$ \\
Pacing board & $\downarrow^{* *}$ & $\uparrow^{* *}$ & & $\uparrow^{*}$ \\
Hand tapping & $\downarrow^{* *}$ & & $\uparrow^{*}$ \\
DAF50 & $\downarrow^{* *}$ & & \\
DAF100 & $\downarrow^{* *}$ & & \\
DAF150 & $\downarrow^{* *}$ & & \\
\hline
\end{tabular}

${ }^{*} \mathrm{p}<0.05 ;{ }^{* *} \mathrm{p}<0.001$

significantly increased mean pause duration $(\mathrm{p}<0.001)$. Finally, only pacing board and hand tapping significantly increased the number of pauses $(p<0.05)$. Note that when using an alphabet board, the number of pauses decreased significantly $(\mathrm{p}<0.05)$.

\section{Intelligibility}

Statistical analysis showed that rate reduction had a significant effect on intelligibility $(\mathrm{p}<0.05)$, as illustrated in figure 2 . The figure clearly shows that the mean intelligibility of the dysarthric population decreased due to each RCM. Although each RCM resulted in lower mean intelligibility ratings, pairwise comparison showed that 
Fig. 2. Effect of RCMs on the intelligibility of dysarthric speakers. Data presented as means $\pm \mathrm{SE}$.

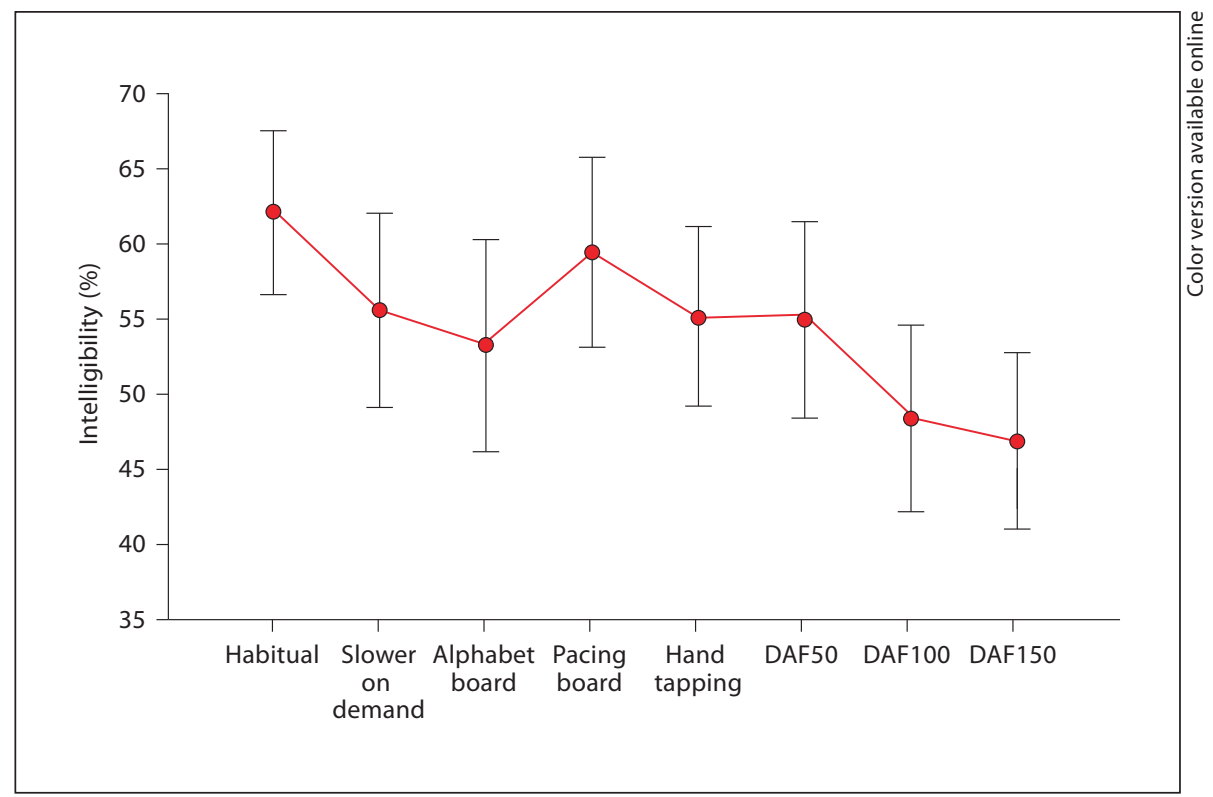

the mutual difference with habitual intelligibility was only significant in case of DAF100 and DAF150 ( $\mathrm{p}<$ 0.05).

Analysis of the individual data (table 4) reveals that rate control did not decrease the intelligibility of every participant. In fact, in almost $50 \%$ of the participants (namely participants $4,5,9,10,11,13,15,16,18,22,25$, 26 and 27), a clinically significant increase (i.e. $>8 \%$ ) was noted secondary to one or more RCMs. Each RCM led to a clinically significant increase in at least 1 participant. Alphabet board, pacing board and hand tapping were the most effective methods with a clinically significant increase in 6, 6 and 8 participants, respectively. Speaking slower on demand increased the intelligibility of 5 participants with more than $8 \%$, both DAF50 and DAF100 did the same in 4 participants and DAF150 in 1 participant.

In 4 participants, intelligibility even improved by more than $20 \%$, with a maximal increase of $59 \%$.

\section{Ideal Speech Rate}

A very important question regarding rate control and its application in clinical practice is: to what extent should we decrease the rate to obtain maximal improvement in intelligibility? In other words, does the phrase 'the slower, the better' apply?

Although the most effective methods, namely hand tapping, pacing board and alphabet board were also the most effective in reducing mean AR and mean SR, the individual data reveal that in general an individual's maximal intelligibility level was not obtained by the method that reduced SR or AR most effectively. A maximal improvement in intelligibility was only associated with maximal decrease in SR or AR in 6 of the 27 participants.

Table 5 presents the habitual ARs and SRs, as well as the ARs and SRs associated with maximal improvement in intelligibility, of the 13 participants whose intelligibility significantly improved. SR associated with an individual's maximal intelligibility ranged from 0.35 to 3.12 syllables/s and the percentage decrease in SR leading to maximal intelligibility varied considerably (4-82\%).

Furthermore, the range of ARs associated with maximal improvement in intelligibility is considerable (1.574.74 syllables/s) and the percentage decreases in AR leading to maximal intelligibility ranged from 3 to $55 \%$.

\section{Characteristics of the Patients Who Benefited from \\ Rate Control}

In order to gain further insight into which type of dysarthric speaker may benefit from rate control, the individual data (table 1) obtained from the 13 participants who showed a clinically significant increase in intelligibility were analyzed.

\section{Habitual Speech Rate}

The data in table 1 reveal that rate control is not only beneficial for individuals with increased habitual SR 
Table 4. Speech intelligibility ratings (\%) according to RCM

\begin{tabular}{|c|c|c|c|c|c|c|c|c|}
\hline Participant & Habitual & $\begin{array}{l}\text { Slower on } \\
\text { demand }\end{array}$ & $\begin{array}{l}\text { Alphabet } \\
\text { board }\end{array}$ & $\begin{array}{l}\text { Hand } \\
\text { tapping }\end{array}$ & $\begin{array}{l}\text { Pacing } \\
\text { board }\end{array}$ & DAF50 & DAF100 & DAF150 \\
\hline 1 & 89.33 & 89.67 & 78.67 & 89.67 & 79.67 & 80.67 & 74.00 & 62.67 \\
\hline 2 & 83.33 & 90.01 & 85.00 & 85.67 & 88.33 & 72.33 & 72.33 & 79.33 \\
\hline 3 & 79.67 & 76.33 & 47.00 & 65.00 & 33.00 & 63.00 & 64.00 & 51.67 \\
\hline 4 & 74.33 & 93.67 & 91.00 & 87.00 & 80.33 & 70.33 & 84.33 & 62.33 \\
\hline 5 & 55.33 & 66.00 & 26.67 & 51.00 & 47.00 & 65.33 & 64.33 & 55.00 \\
\hline 6 & 69.67 & 51.00 & 6.00 & 2.33 & 0.33 & 17.00 & 57.33 & 5.67 \\
\hline 7 & 45.33 & 8.67 & 8.67 & 24.33 & 1.00 & 10.00 & 8.33 & 2.00 \\
\hline 8 & 88.00 & 75.33 & 90.67 & 74.00 & 84.33 & 73.00 & 80.00 & 85.67 \\
\hline 9 & 45.33 & 49.00 & 10.00 & 56.67 & 58.00 & 54.00 & 37.33 & 32.67 \\
\hline 10 & 88.00 & 96.33 & 27.67 & 79.00 & 67.33 & 89.67 & 82.00 & 63.00 \\
\hline 11 & 51.33 & 39.00 & 83.67 & 53.00 & 60.67 & 47.33 & 36.33 & 43.00 \\
\hline 12 & 85.67 & 71.00 & 80.67 & 91.67 & 77.33 & 87.33 & 62.67 & 59.67 \\
\hline 13 & 81.33 & 73.67 & 54.00 & 49.33 & 88.00 & 91.00 & 84.00 & 81.00 \\
\hline 14 & 19.67 & 17.33 & - & 6.00 & - & 14.67 & 1.67 & 1.67 \\
\hline 15 & 67.33 & 96.33 & 100.00 & 92.00 & 99.33 & 96.00 & 90.67 & 61.67 \\
\hline 16 & 2.33 & 0.00 & 0.00 & 13.33 & 0.00 & 1.00 & 0.00 & 0.00 \\
\hline 17 & 51.67 & 32.33 & 28.00 & 26.00 & 53.33 & 14.00 & 32.00 & 50.00 \\
\hline 18 & 55.00 & 13.67 & 6.67 & 68.67 & 87.33 & 1.33 & 5.33 & 3.67 \\
\hline 19 & 87.33 & 86.00 & 68.33 & 88.33 & 78.33 & 70.67 & 57.33 & 70.33 \\
\hline 20 & 82.67 & 46.00 & 83.67 & 69.67 & 61.00 & 87.00 & 79.67 & 84.33 \\
\hline 21 & 87.67 & 44.33 & 92.33 & 65.67 & 77.67 & 86.67 & 52.00 & 62.00 \\
\hline 22 & 79.00 & 68.67 & 92.33 & 65.33 & 60.67 & 84.00 & 35.33 & 86.67 \\
\hline 23 & 3.00 & 0.00 & 5.67 & 0.00 & 0.00 & 1.67 & 0.00 & 0.00 \\
\hline 24 & 84.00 & 87.67 & 57.67 & 11.00 & 75.33 & 74.67 & 31.00 & 36.33 \\
\hline 25 & 84.33 & 95.00 & 94.33 & 93.33 & 96.67 & 90.33 & 98.00 & 83.33 \\
\hline 26 & 11.33 & 7.33 & 3.33 & 21.00 & 8.67 & 18.00 & 5.33 & 20.33 \\
\hline 27 & 22.67 & 26.33 & 62.67 & 60.00 & 81.67 & 23.33 & 9.67 & 21.67 \\
\hline
\end{tabular}

Table 5. SR and AR (habitual/maximal intelligibility) and decrease in AR and SR leading to the maximal intelligibility of the 13 subjects with significantly improved intelligibility

\begin{tabular}{|c|c|c|c|c|c|c|}
\hline $\begin{array}{l}\text { Participant } \\
\text { No. }\end{array}$ & $\begin{array}{l}\text { SR habitual, } \\
\text { syllables/s }\end{array}$ & $\begin{array}{l}\text { SR max. } \\
\text { intelligibility, } \\
\text { syllables/s }\end{array}$ & Decrease, \% & $\begin{array}{l}\text { AR habitual, } \\
\text { syllables/s }\end{array}$ & $\begin{array}{l}\text { AR max. } \\
\text { intelligibility, } \\
\text { syllables/s }\end{array}$ & Decrease, \% \\
\hline 4 & 3.27 & 2.85 & 13 & 4.24 & 4.09 & 5.5 \\
\hline 5 & 2.73 & 2.62 & 4 & 5.86 & 5.67 & 3 \\
\hline 9 & 3.47 & 1.13 & 68 & 4.99 & 3.31 & 34 \\
\hline 10 & 2.62 & 2.70 & - & 3.68 & 3.86 & - \\
\hline 11 & 2.30 & 0.43 & 81 & 3.49 & 1.92 & 45 \\
\hline 13 & 3.43 & 3.12 & 9 & 6.14 & 4.74 & 23 \\
\hline 15 & 2.1 & 0.42 & 80 & 2.92 & 1.92 & 34 \\
\hline 16 & 4.97 & 1.66 & 67 & 5.08 & 3.83 & 25 \\
\hline 18 & 4.73 & 1.12 & 76 & 5.39 & 3.42 & 36.5 \\
\hline 22 & 1.93 & 0.35 & 82 & 3.18 & 1.93 & 40 \\
\hline 25 & 2.28 & 1.97 & 14 & 3.93 & 2.84 & 28 \\
\hline 26 & 1.66 & 0.75 & 55 & 2.19 & 1.57 & 28 \\
\hline 27 & 4.17 & 1.1 & 74 & 4.22 & 1.9 & 55 \\
\hline
\end{tabular}


and/or AR. Only 2 of the 13 participants with significantly improved intelligibility had increased SRs and only 1 had an increased AR. Thus, the majority of these participants had either normal or decreased SRs and ARs. Moreover, for 4 of the 6 participants with decreased SR, a further decrease in intelligibility was beneficial. The same was true for 3 out of 6 participants with decreased AR.

\section{Type of Dysarthria}

The limited number of participants per subtype of dysarthria does not allow for statistical analysis. However, analysis of table 1 shows that significant improvements in intelligibility were found in 5 participants with hypokinetic dysarthria, 5 with UUMND, 2 with ataxic dysarthria and 1 with mixed dysarthria.

\section{Severity of Dysarthria and Degree of Intelligibility}

To investigate whether the effect of rate control on intelligibility depends on the severity of dysarthria, the effect of the 7 RCMs on the intelligibility of participants with mildly impaired speech $(n=12)$ was compared with their effect on the intelligibility of participants with moderately or severely impaired speech $(n=15)$ by means of separate independent-sample t tests. A significant difference $(p<0.05)$ between both groups was only found for slower on demand and DAF100. Both methods were more beneficial for individuals with mildly impaired speech when compared to individuals with moderately or severely impaired speech.

Seven of the 13 participants with significantly improved intelligibility were judged as mildly, 5 as moderately and 1 as severely impaired dysarthric speakers. Their intelligibility ranged from 11 to $88 \%$.

\section{Discussion}

\section{Effect of Rate Control on $A R$ and $S R$}

This study revealed that - with exception of speaking slower on demand - each investigated RCM significantly decreased the mean AR and mean SR of the dysarthric population. These results are in accordance with those of other studies [11-20] and our previous study [5], and confirm that most RCMs applied in clinical practice to reduce speech rate are effective. The RCMs that most effectively reduced AR and SR were pacing board, hand tapping and alphabet board.

Table 3 clearly visualizes in which way each of the investigated RCMs affects SR. Three categories of RCMs can be distinguished. Category 1 only contains speaking slower on demand and does not significantly change AR, pause duration or pause frequency. The effect of DAF on SR is obviously the result of its effect on AR. The last category consists of those methods that affect both AR and pause duration and/or pause frequency, namely alphabet board, pacing board and hand tapping. Note that these methods do not change SR in exactly the same way. Whereas using an alphabet board increases total pause duration and mean pause duration, the use of a pacing board increases total pause duration and pause frequency and hand tapping only increases pause frequency.

Some attention should be paid to the limited effect that speaking slower on demand has on AR and SR. Although the participants were asked to speak half as fast as they were used to, on average, they only reduced their SR by $9 \%$ and their AR by nearly $4 \%$. Two other studies that investigated the effect of speaking slower on demand on speech rate and intelligibility, using the same methods as the current study, revealed greater changes in AR and SR. Turner et al. [12] registered a decrease in SR of $21 \%$, but noted that the percentage decrease in the dysarthric population was only half the decrease registered for the neurologically intact group. Tjaden and Wilding [11] found decreases in AR of 23 and $31 \%$ for individuals with dysarthria due to multiple sclerosis and Parkinson's disease, respectively. Although the decreases in AR and SR observed in those studies are obviously greater, the dysarthric populations did not reduce their rates by $50 \%$ and only reduced their rates half as much as neurologically intact speakers. Thus, the question is whether the limited effect of speaking slower on demand on AR and SR in the current study is due to the study design (i.e. no modeling and limited feedback) rather than to the skills of the dysarthric speaker. Yorkston et al. [21] stated that few speakers with dysarthria can reduce their SR and maintain a slowed rate after simply being instructed to 'slow down'. Since speaking slower on demand is the most natural $\mathrm{RCM}$, this issue deserves further investigation.

Finally, little is known about the ideal delay for DAF. Regarding AR, although the mean AR decreased with increasing delay (fig. 1), no significant differences between DAF50, DAF100 and DAF150 were found. Moreover, no significant effect of delay on SR was found.

\section{Effect of Rate Control on Intelligibility}

For the whole study group, each RCM resulted in significantly lower mean levels of intelligibility $(\mathrm{p}<0.05)$. These group results are clearly reflected in the individual data, revealing that rate control may have the opposite effect on intelligibility. Rate control significantly decreased 
intelligibility in 22 of the 27 participants. When using a pacing board, alphabet board and hand tapping, this effect may be explained by the fact that these methods require a certain degree of attention and coordination. The influence of these actions may be high since the subjects were not familiar with the methods. The same may be true for DAF $[16,20]$. These presumptions obviously need further investigation in order to verify them.

As discussed in the previous paragraphs, rate control can have the opposite effect on the intelligibility of dysarthric speech. However, analysis of the individual data showed that a clinically significant improvement in intelligibility was registered in almost $50 \%$ of the individuals with dysarthria. Strikingly, the most effective methods (hand tapping, pacing board and alphabet board) all affect SR by reducing AR and increasing pause duration and/or pause frequency and these methods all set boundaries (i.e. word or syllable boundaries). As a consequence, these methods facilitate the 3 speech perception processes of the listener, namely lexical activation (activation of certain words based on segmental information provided by the acoustic signal), lexical competition (which word matches best with the perceived acoustic signal?) and lexical segmentation (dividing the stream of acoustic information into separate words) [22].

Whereas only slower on demand, alphabet board, pacing board and hand tapping led to significantly increased intelligibility in the initial study [5], the extended data reveal that each of the investigated RCMs is able to significantly improve intelligibility of dysarthric speech.

As mentioned previously, little is known about the ideal delay for DAF. Figure 2 shows that the mean intelligibility of the dysarthric population further decreased with increasing delay. At the individual level, DAF50 and DAF100 both significantly increased $(+>8 \%)$ the intelligibility of 4 participants, whereas DAF150 only significantly increased intelligibility in 1 individual. These results indicate that in general DAF50 and DAF100 are more effective, but when considering an individual patient a higher delay might sometimes be more effective.

\section{Ideal Speech Rate}

Little is known about the ideal SR or AR with regard to intelligibility. Yorkston et al. [23] found in 4 individuals with ataxic dysarthria and 4 individuals with hypokinetic dysarthria that a decrease in SR (down to $60 \%$ of the habitual SR) resulted in higher intelligibility levels than speaking at $80 \%$ of the habitual SR. However, does this imply that maximal intelligibility is achieved by maximally decreasing SR and/or AR? The individual data of the current study indicate that this does not hold true. Only in 6 of the 27 participants was the highest degree of intelligibility obtained as a result of the RCM that most effectively reduced SR and/or AR.

Liss [22] even argued that speaking too slowly can have an adverse effect on intelligibility. Speaking too slow may negatively influence the listener's speech perception strategies by affecting prosody and demanding too much of the listener's short-term memory. However, whereas the individual data do not reveal a critical upper boundary for AR and SR, they also do not reveal a critical lower boundary. In addition, it is not possible to withdraw a reference for an ideal speech rate, neither in terms of a concrete number nor in terms of percentage decrease in AR or SR.

\section{Characteristics of Patients Who May Benefit from Rate Control}

Although the number of participants in the various subgroups is rather limited and thus insufficient for statistical analysis, the individual data do reveal some interesting information regarding the type of dysarthric patient that may benefit from rate control.

First, the results point out that the beneficial effect of rate control is not limited to patients who speak too fast. The majority of the participants with significantly improved intelligibility had SRs and ARs within normal boundaries or even decreased rates. These results add credence to the results of the initial study [5] and the findings of Jaeger et al. [24] who found that individuals with dysarthria tend to speak near the upper limit of their SR.

When it comes to the type of dysarthria, the literature has mainly reported on individuals with a hypokinetic dysarthria $[11,14-17,20,23,25-28]$ and to a lesser extent ataxic dysarthria $[6,14,23]$. This is probably due to the fact that hypokinetic dysarthria is associated with increased speech rate, and the fact that modifying rate and prosody is described as one of the most important aspects of behavioral therapy in ataxic dysarthria [1]. This study revealed that apart from individuals with a hypokinetic and ataxic dysarthria, individuals with UUMND and mixed dysarthria may also benefit from rate control. Two other studies reported a positive effect of rate control in a total of 6 individuals with mixed dysarthria $[12,18]$. These results suggest that the positive effect of rate control is not restricted to hypokinetic and ataxic dysarthria and that various types of dysarthria may benefit from rate control. This obviously requires further investigation. 
Finally, the results show that the effect of rate control is not greater in individuals with moderately or severely impaired speech compared to individuals with mild dysarthria.

\section{Implications for Clinical Practice}

The data of this study and the data available in literature reveal some important implications for clinical practice. First of all, rate control should be considered as a therapeutic method in each individual with dysarthria, independently of the habitual speech rate, severity of dysarthria and type of dysarthria. Secondly, clinicians should keep in mind that each RCM has the potential to improve intelligibility, but pacing, hand tapping and alphabet board were found to be the most effective methods. And finally, a maximal decrease in speech rate does not always lead to maximal improvement of intelligibility. Based on the current knowledge, it is recommended to judge the effect of rate control for a specific individual with dysarthria during a trial session, trying out different methods and different rates.

\section{Conclusions}

The results of the current study reveal that each of the investigated RCMs decrease both SR and AR. However, in the case of speaking slower on demand, this decrease is limited and not significant.
When it comes to speech intelligibility, the results show that each RCM can establish a significant improvement in intelligibility. The most effective methods were hand tapping, pacing board and alphabet board. It is striking that these methods all affect SR by reducing AR and increasing pause duration and/or pause frequency, and that the methods all set boundaries at the word or syllable level. The results of this study also indicate that the effect of rate control on intelligibility does not depend on the habitual speech rate or severity of dysarthria. Based on the current results and some data in literature, it can also be suggested that rate control may be beneficial for various types of dysarthria. Furthermore, it is not possible to conclude upon an ideal speech rate. However, this study does reveal that maximally decreased rate is not always associated with maximally improved intelligibility. Finally, it should be mentioned that although rate control may improve intelligibility in dysarthria, it may also have the opposite effect on intelligibility in some cases.

\section{Acknowledgments}

This work was supported by the Flemish Institute for the Promotion of Innovation by Science and Technology in Flanders (IWT, contract SBO/40102). The authors also acknowledge the help of their colleagues Nele Wallyn, Sarah Van Der Donck, Charlotte Vandevoorde and Lize Vanhie who assisted in the data collection, and their colleague Cindy Guns for judging the audio samples.

\section{References}

1 Duffy JR: Motor Speech Disorders. St. Louis, Elsevier Mosby, 2005.

2 Marshall RC, Karow C: Retrospective examination of failed rate-control intervention. Am J Speech Lang Path 2002;11:3-16.

3 Yorkston KM, Dowden PA, Beukelman D: Intelligibility as a tool in the clinical management of dysarthric speakers; in Kent RD (ed): Intelligibility in Speech Disorders: Theory, Measurement and Management. Amsterdam, John Benjamin, 1992, pp 265-286.

4 Yorkston KM, Hakel M, Beukelman DR, et al: Evidence for effectiveness of treatment of loudness, rate, or prosody in dysarthria: a systematic review. J Med Speech Lang Path 2007;15:11-36.

5 Van Nuffelen G, De Bodt M, Wuyts F, Van de Heyning P: The effect of rate control on speech rate and intelligibility of dysarthric speech. Folia Phoniatr Logop 2009;61:69-75.
6 Visser J, van Laarhoven A, ter Beek A: AVIToetspakket Handleiding. Hertogenbosch, KPC, 1994.

7 Duffy JR: History, current practice, and future trends and goals; in Weismer G (ed): Motor Speech Disorders. San Diego, Plural, 2007, pp 7-56.

$\checkmark 8$ Kent RD, Weismer G, Kent JF, Rosenbek JC: Toward phonetic intelligibility testing in dysarthria. J Speech Hear Disord 1989;54: 482-499.

9 Yorkston KM, Beukelman DR: A clinicianjudged technique for quantifying dysarthric speech based on single-word intelligibility. J Commun Disord 1980;13:15-31.

$\checkmark 10$ Yorkston KM, Strand EA, Kennedy MRT: Comprehensibility of dysarthric speech: implications for assessment and treatment planning. Am J Speech Lang Path 1996;5:5566
11 Tjaden K, Wilding GE: Rate and loudness manipulations in dysarthria: acoustic and perceptual findings. J Speech Lang Hear Res 2004;47:766-783.

12 Turner GS, Tjaden K, Weismer G: The influence of speaking rate on vowel space and speech intelligibility for individuals with amyotrophic lateral sclerosis. J Speech Hear Res 1995;38:1001-1013.

13 Hustad KC, Sassano K: Effects of rate reduction on severe spastic dysarthria in cerebral palsy. J Med Speech Lang Path 2002;10:287292.

14 Dagenais PA, Southwood MH, Mallonee KO: Assessing processing skills in speakers with Parkinson's disease using delayed auditory feedback. J Med Speech Lang Path 1999;7: 297-313.

15 Hanson WR, Metter EJ: DAF as instrumental treatment for dysarthria in progressive supranuclear palsy: a case report. J Speech Hear Disord 1980;45:268-276. 
16 Rousseau B, Watts CR: Susceptibility of speakers with Parkinson disease to delayed feedback. J Med Speech Lang Path 2002;10: 41-49.

17 Hanson W, Metter E: DAF speech rate modification in Parkinson's disease: a report of two cases; in Berry W (ed): Clinical Dysarthria. Austin, Pro-Ed, 1983, pp 231-254.

$\checkmark 18$ Pilon MA, McIntosh KW, Thaut MH: Auditory versus visual speech timing cues as external rate control to enhance verbal intelligibility in mixed spastic-ataxic dysarthric speakers: a pilot study. Brain Inj 1998;12: 793-803.

-19 Yorkston KM, Beukelman DR: Ataxic dysarthria: treatment sequences based on intelligibility and prosodic considerations. J Speech Hear Disord 1981;46:398-404.
20 Dagenais PA, Southwood MH, Lee TL: Rate reduction methods for improving speech intelligibility of dysarthric speakers with Parkinson's disease. J Med Speech Lang Path 1998;6:143-157.

21 Yorkston KM, Beukelman DR, Strand EA, Bell K: Management of motor speech disorders in children and adults. Austin, Pro-Ed, 1999.

22 Liss JM: The role of speech perception in motor speech disorders; in Weismer G (ed): Motor Speech Disorders. San Diego, Plural, 2007, pp 187-219.

23 Yorkston KM, Hammen VL, Beukelman DR Traynor CD: The effect of rate control on the intelligibility and naturalness of dysarthric speech. J Speech Hear Disord 1990;55:550560.

-24 Jaeger M, Hertrich I, Stattrop U, Schonle PW, Ackermann H: Speech disorders following severe traumatic brain injury: kinematic analysis of syllable repetitions using electromagnetic articulography. Folia Phoniatr Logop 2000;52:187-196.
25 Hammen VL, Yorkston KM, Minifie FD: Effects of temporal alterations on speech intelligibility in parkinsonian dysarthria. J Speech Hear Res 1994;37:244-253.

26 Adams SG: Hypokinetic dysarthria in Parkinson's disease; in McNeil MR (ed): Clinical Management of Sensorimotor Speech Disorders. New York, Thieme, 1997, pp 261-286.

$>27$ Downie AW, Low JM, Lindsay DD: Speech disorder in parkinsonism - usefulness of delayed auditory feedback in selected cases. $\mathrm{Br}$ J Disord Commun 1981;16:135-139.

28 Le Dorze G, Dionne L, Ryalls J, Julien M, Ouellet L: The effects of speech and language therapy for a case of dysarthria associated with Parkinson's disease. Eur J Disord Commun 1992;27:313-324. 